\title{
Formation of Mg-Ni Hydrogen Absorption Alloy Film by Molten Salts Electrolysis
}

\author{
Hiroaki YAMAMOTO, ${ }^{\text {a }}$ Atsushi KAWAKAMI, ${ }^{\text {a }}$ Kensuke KURODA, ${ }^{b}$ \\ Ryoichi ICHINO, ${ }^{\mathrm{c}}$ and Masazumi OKIDO ${ }^{\mathrm{b}}$
}

\begin{abstract}
${ }^{a} G r a d u a t e ~ S t u d e n t$, Graduate School of Engineering, Nagoya University (Furo-cho, Chikusa-ku, Nagoya 4648603, Japan)

${ }^{b}$ Center for Integrated Research in Science and Engineering, Nagoya University

${ }^{\mathrm{c}}$ Graduate School of Engineering, Nagoya University
\end{abstract}

Received December 2, 1998 ; Accepted December 25, 1998

\begin{abstract}
A Magnesium-Nickel hydrogen absorption alloy, $\mathrm{Mg}_{2} \mathrm{Ni}$, was produced as a film by molten salts electrolysis and diffusion process. Magnesium was electrodeposited on a nickel substrate from a $25 \mathrm{~mol} \% \mathrm{NaCl}-5 \mathrm{~mol} \% \mathrm{KCl}$ $-70 \mathrm{~mol} \% \mathrm{CaCl}_{2}$ mixture as a supporting electrolyte, and additionally $10 \mathrm{~mol}_{\%} \mathrm{MgCl}_{2}$ with respect to the supporting electrolyte as magnesium-ion source. The electrodeposition was conducted at $873 \sim 1073 \mathrm{~K}$ and with cathodic current densities between $0.02 \sim 0.10 \mathrm{~A} \mathrm{~cm}^{-2}$ for $3.6 \sim 18 \mathrm{ks}$. After the electrolysis, the specimens were subjected to X-ray diffraction and EPMA line analysis to identify the phase of compounds and to measure the thickness of the film. As a result, only hydrogen absorption alloy films, $\mathrm{Mg}_{2} \mathrm{Ni}$, were obtained with $20 \mu \mathrm{m}$ and $27 \mu \mathrm{m}$ thickness from electrodeposition with $0.10 \mathrm{~A} \mathrm{~cm}^{-2}$ for $3.6 \mathrm{ks}$ at $1023 \mathrm{~K}$ and with $0.02 \mathrm{~A} \mathrm{~cm} \mathrm{~cm}^{-2}$ for $18 \mathrm{ks}$ at $873 \mathrm{~K}$, respectively. At $1073 \mathrm{~K}$, the intermetallic compound $\mathrm{MgNi}_{2}$ was also detected between the $\mathrm{Mg}_{2} \mathrm{Ni} \mathrm{layer}$ and the nickel substrate. These specimens were subjected to hydrogen absorption tests in $30 \mathrm{mass} \% \mathrm{KOH}$ solution at $298 \mathrm{~K}$. It was confirmed that these specimens absorbed hydrogen.
\end{abstract}

Key Words : Molten Salts Electrolysis, Hydrogen Absorption Alloy, $\mathrm{Mg}_{2} \mathrm{Ni}$

\section{Introduction}

Much attention has been paid to hydrogen absorption alloys, because, for example, batteries using them as cathodic material are clean and safe in terms of a low environmental impact and have a high capacity. A lot of improvements have been tried to develop a new production method for hydrogen absorption alloy.1) As a bulk material, hydrogen absorption alloys are generally produced by the melting method of the pure metals mixture in a furnace, arc-melting method, etc. It is reported that mechanical alloying method and sputtering method were available to make the powder and the thin film alloy with better hydrogen absorption properties than bulk materials, respectively. ${ }^{2-4)}$

Considering the majority of the binary hydrogen absorption alloys, they consist of metal A, which forms hydride easily, and metal B, which oppositely forms hydride uneasily. Although it is impossible, in general case, to electrodeposit metal A such as lanthanum, calcium, titanium, magnesium, etc. from the aqueous solution, these metals can be obtained by molten salts electrolysis. Thus, a combined process with molten salts electrolysis and diffusion, i.e. alloying electrodeposits with the substrate, has been proposed to produce hydrogen absorption alloy films. ${ }^{5)}$ This process has the following advantages: (i) The hydrogen absorption alloy is formed as a film on the substrate in a direct and single process from chloride, fluoride or oxide resources without using costly and active metals, e.g. pure lanthanum, calcium and magnesium metals, (ii) Mass production of the film is easy. The production of the hydrogen absorption films such as $\mathrm{LaNi}_{5}, \mathrm{CaNi}_{5}$ and TiFe by using this process, and the evaluation of hydrogen absorption-desorption properties were reported in previous papers. ${ }^{5-7)}$

This paper is focused on $\mathrm{Mg}-\mathrm{Ni}$ hydrogen absorption alloys, which have been reported to have high theoretical hydrogen absorption capacity and have a lower cost than other alloys. ${ }^{8)}$ The electrolysis process to obtain the alloys and the relationship between the electrolysis conditions and the formed alloy phase are examined in this works.

\section{Experimental Theory}

A schematic illustration of the formation process of the intermetallic compound on the substrate is shown in Fig. 1. When the substrate B is immersed into a molten salts containing $\mathrm{A}$ ions and a cathodic current 


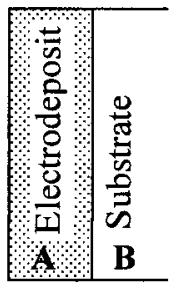

(1)

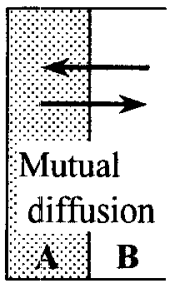

(2)

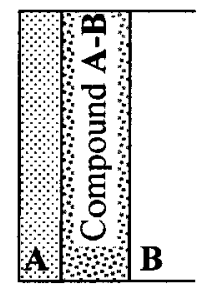

(3)

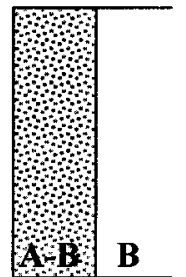

(4)

Fig. 1 Schematic illustration of the formation process of the intermetallic compound A-B.

is passed, metal A is electrodeposited on the substrate B (Fig. 1 (1)). If mutual diffusion and a chemical reaction occur between the electrodeposit $A$ and the substrate B (Fig. 1 (2)), an intermetallic compound $\mathrm{A} \cdot \mathrm{B}$ is formed (Fig. 1 (4)). In the alloying process between $A$ and $B$, if the mutual diffusion of $A$ into $B$ or $B$ into $A$ is the rate-determining step, the metal phase A must remain on the surface of the specimen (Fig. 1 (3) ). The rate-determining step in the reaction determines whether the A-B alloy layer consists of single- or multi-layer. That is to say, the alloy phase formed on the substrate should be determined by the experimental conditions such as temperature, current density and electrolysis time.

\section{Experimental}

Magnesium was electrodeposited on a nickel sub strate, which has a surface area of $15 \times 15 \mathrm{~mm}^{2}$ and $0.1 \mathrm{~mm}$ thickness, from a $25 \mathrm{~mol} \% \mathrm{NaCl}^{-} 5 \mathrm{~mol} \%$ $\mathrm{KCl}-70 \mathrm{~mol}_{\%} \mathrm{CaCl}_{2}$ mixture as a supporting electrolyte and additionally $10 \mathrm{~mol} \% \mathrm{MgCl}_{2}$ with respect to the supporting electrolyte as a $\mathrm{Mg}$-ion source. The experimental apparatus is the same described in the previous paper. ${ }^{5}$. The reference electrode was a silver wire immersed in $\mathrm{NaCl}-\mathrm{KCl}-\mathrm{CaCl}_{2}$ (25-5-70 mol $\%)$ containing $10 \mathrm{~mol} \% \mathrm{AgCl}$ in a mullite tube. The constituent salts were weighed, mixed, dried for $172.8 \mathrm{ks}$ ( 2 days) at $373 \mathrm{~K}$ and dehydrated by heating slowly up to the experimental temperature and kept it for $3.6 \mathrm{ks}$. The substrate was polished with the waterproof abrasive paper \#1000, degreased with acetone and using an ultra sonic cleaner, and heated in molten salts for $1.8 \mathrm{ks}$ at temperatures higher than $973 \mathrm{~K}$. Before the experiment, the pre-electrolysis was carried out in order to remove some impurities and moisture from the molten salts. Molten salts electrolysis were conducted under the electrolysis conditions as follows : Current density was $0.02 \sim 0.10$ $\mathrm{A} \mathrm{cm}^{-2}$, electrolysis time was $3.6 \sim 18 \mathrm{ks}$, and temperature was $873 \sim 1073 \mathrm{~K}$. After the electrolysis, the specimen was cooled to room temperature in a furnace under argon atmosphere for about $25.2 \mathrm{ks}$ (7 hours). The specimens were subjected to X-ray diffraction analysis and EPMA line analysis to identify

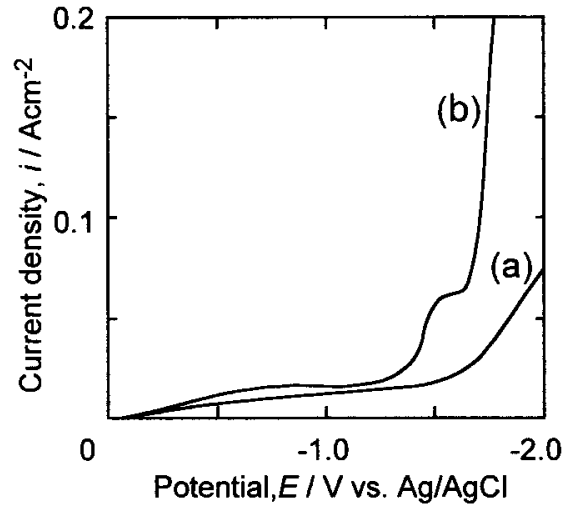

Fig. 2 Cathodic polarization curves of the nickel substrate in $\mathrm{NaCl}-\mathrm{KCl}-\mathrm{CaCl}_{2}-\mathrm{MgCl}_{2}$ molten salts without $\mathrm{MgCl}_{2}$ (a) and with $10 \mathrm{~mol} \% \mathrm{MgCl}_{2}$ (b) at $873 \mathrm{~K}$ with a scanning rate of $0.1 \mathrm{~V} \mathrm{~s}^{-1}$.

the alloy phase formed on the substrate and to measure the thickness.

The hydrogen absorption test was conducted in a 30 mass \% $\mathrm{KOH}$ solution at $298 \mathrm{~K}$. The experimental method and apparatus to evaluate hydrogen absorption properties for alloy films produced by molten salts electrolysis were also described in the previous paper. ${ }^{5)}$

\section{Results and Discussion}

4. 1 Formation of hydrogen absorption alloys by molten salts electrolysis

4. 1. 1 Cathodic polarization curves The cathodic polarization curves of the nickel substrate in $\mathrm{NaCl}-\mathrm{KCl}-\mathrm{CaCl}_{2}-\mathrm{MgCl}_{2}$ molten salts at $873 \mathrm{~K}$ with a scan rate of $0.1 \mathrm{Vs}^{-1}$ are shown in Fig. 2. In curve (a) measured in the molten salts containing no magnesium ion source, the current increases rapidly at about $-1.7 \mathrm{~V}$ vs. $\mathrm{Ag} / \mathrm{AgCl}$ reference electrode. In curve (b) measured in the molten salts containing 10 mol \% $\mathrm{MgCl}_{2}$, the current, however, increases at about $-1.4 \mathrm{~V}$. This means that magnesium deposition starts at a potential of $-1.4 \mathrm{~V}$. Figure 3 shows the cathodic polarization curves measured at $973 \mathrm{~K}$ 


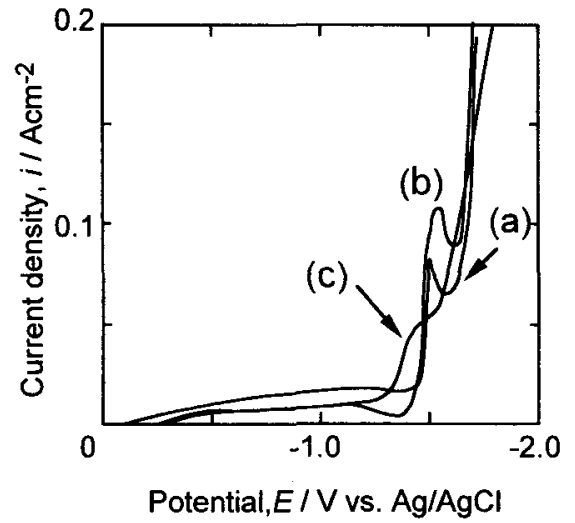

Fig. 3 Cathodic polarization curves of the nickel substrate in $\mathrm{NaCl}-\mathrm{KCl}-\mathrm{CaCl}_{2}-\mathrm{MgCl}_{2}$ molten salts. Scan rate : $0.1 \mathrm{~V} \mathrm{~s}^{-1}$. These curves were measured at $973 \mathrm{~K} \mathrm{(a),} \mathrm{at} 1023$ $\mathrm{K}(\mathrm{b})$, and at $1073 \mathrm{~K}$ (c).

(a), $1023 \mathrm{~K}$ (b), and $1073 \mathrm{~K}$ (c). It was found that the cathodic current peaks corresponding to magnesium electrodeposition are observed at $c a . \quad-1.5 \mathrm{~V}$ in any curves. Therefore, these curves in Fig. 2 and Fig. 3 prove that magnesium is electrodeposited on the nickel substrate from the molten $\mathrm{NaCl}-\mathrm{KCl}-\mathrm{CaCl}_{2}$ $\mathrm{MgCl}_{2}$ salts.

4. 1. $2 \mathrm{X}$-ray diffraction and EPMA line analysis

X-ray diffraction patterns of the surface of the specimen electrodeposited at $873 \mathrm{~K}$ in a few current densities and durations with a constant cathodic electricity of $1620 \mathrm{C}$, i.e., with $0.10 \mathrm{~A} \mathrm{~cm}^{-2}$ for $3.6 \mathrm{ks}$ (1), with $0.05 \mathrm{~A} \mathrm{~cm}^{-2}$ for $7.2 \mathrm{ks}$ (2), and with 0.02
$\mathrm{A} \mathrm{cm}^{-2}$ for $18 \mathrm{ks} \mathrm{(3),} \mathrm{are} \mathrm{shown} \mathrm{in} \mathrm{Fig.} 4$ (a). EPMA line analysis of the cross section of specimens (1) and (3) are shown in Fig. 4 (b). The cross section of specimen (2) showed the transitive figure between specimens (1) and (3). In any electrolysis conditions, the intermetallic compound, $\mathrm{Mg}_{2} \mathrm{Ni}$, was formed on the nickel substrate. However, the mixture phase of magnesium and $\mathrm{Mg}_{2} \mathrm{Ni}$ was also observed on the top of the surface in cases of specimens (1) and (2). This result corresponds to the phase structure consisting of layer-by-layer as shown in Fig. 1 (3). On the other hand, in the case of electrolysis with a low current density and a long time, i.e. with $0.02 \mathrm{~A} \mathrm{~cm}^{-2}$ for 18 $\mathrm{ks}$, only the $\mathrm{Mg}_{2} \mathrm{Ni}$ phase was observed with $27 \mu \mathrm{m}$ thickness and there was no mixed phase on the surface. This result corresponds to Fig. 1 (4). It is considered that magnesium remained on the surface and this followed to form the mixed phase of magnesium and $\mathrm{Mg}_{2} \mathrm{Ni}$, since time was not enough for magnesium to react with nickel, that is, because of a higher deposition rate than diffusion and / or chemical reaction rate. It is said that the difference of the magnesium electrodeposition rate corresponding to the current density causes the difference of the composition of the formed alloy.

The effect of the cooling process after the electrolysis was investigated by the rapid cooling of the specimen electrodeposited with $0.02 \mathrm{~A} \mathrm{~cm}^{-2}$ for $3.6 \mathrm{ks}$ at $873 \mathrm{~K}$. The specimen was cooled rapidly by helium gas, and then subjected to X-ray diffraction analysis.

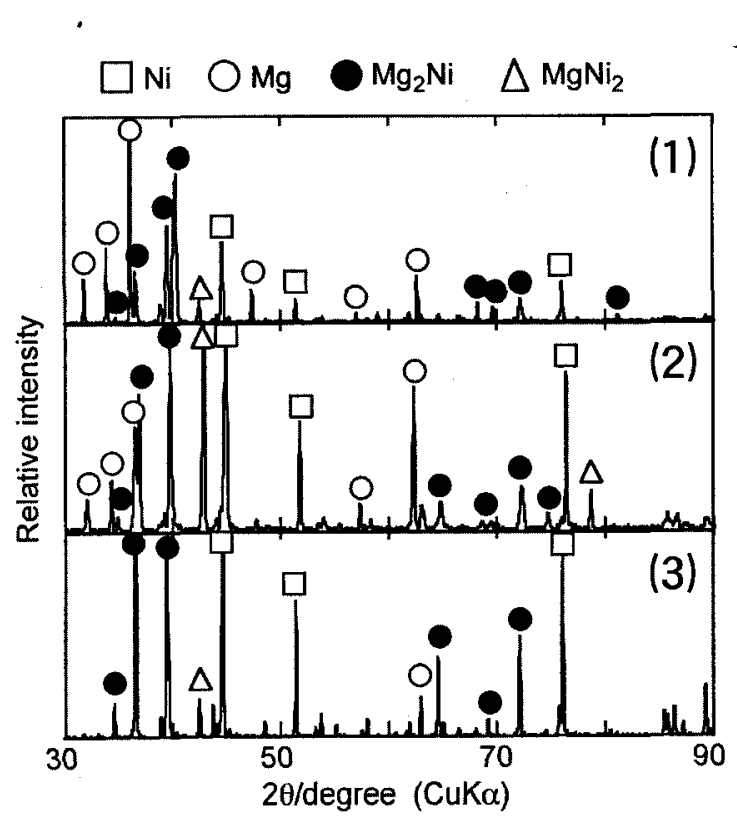

(a)

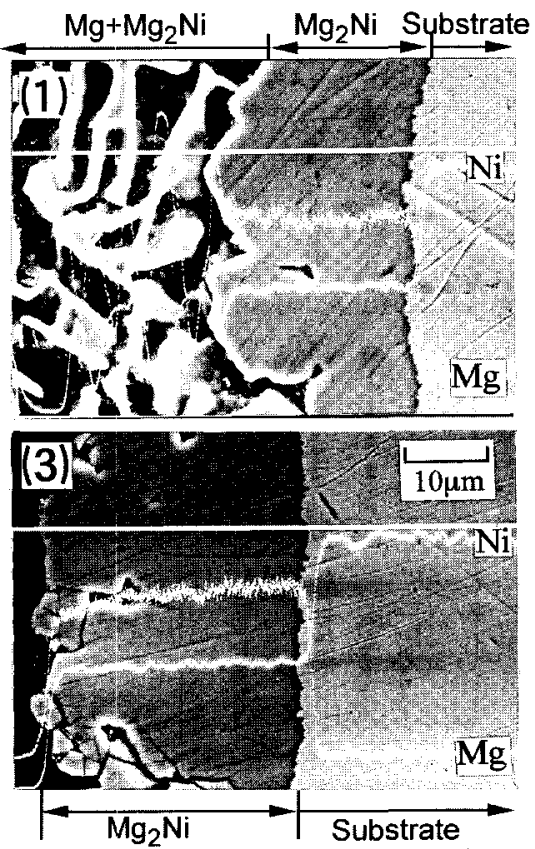

(b)

Fig. 4 X-ray diffraction patterns of the surface (a) and EPMA line analysis of the cross section of specimens (b) electrodeposited at $873 \mathrm{~K}$ with $0.10 \mathrm{~A} \mathrm{~cm}^{-2}$ for $3.6 \mathrm{ks}(1)$, with $0.05 \mathrm{~A} \mathrm{~cm}^{-2}$ for $7.2 \mathrm{ks}$ (2), and with $0.02 \mathrm{~A} \mathrm{~cm}-2$ for $18 \mathrm{ks}(3)$. 
The diffraction peaks of $\mathrm{Mg}_{2} \mathrm{Ni}$ and magnesium, which were not observed in the case of slow cooling rate, were observed in this case. This result showed that reaction time is the sum of the electrolysis time and cooling time.

The electrolysis temperature is one of the factors to affect the reaction rate of the electrodeposited magnesium with the nickel substrate. Thus, magnesium electrodeposition at several different temperatures was conducted with $0.10 \mathrm{~A} \mathrm{~cm}^{-1}$ for $3.6 \mathrm{ks}$. X-ray diffraction patterns of the surface and EPMA line analysis of the cross section of specimens electrodeposited at $973 \mathrm{~K}(1), 1023 \mathrm{~K}(2)$ and $1073 \mathrm{~K}$ (3) are shown in Fig. 5. Magnesium and $\mathrm{Mg}_{2} \mathrm{Ni}$ mixed phase observed in the specimen electrodeposited at $873 \mathrm{~K}$ in Fig. 4 (b) (1) was not observed in the specimen electrodeposited at $1023 \mathrm{~K}$ in Fig. 5 (b) (2). Only the $\mathrm{Mg}_{2} \mathrm{Ni}$ phase with about $20 \mu \mathrm{m}$ thickness was formed at $1023 \mathrm{~K}$. It is considered that the alloying reaction rate at $1023 \mathrm{~K}$ is faster than at $873 \mathrm{~K}$, thus magnesium is not left on the surface. But at higher temperature of $1073 \mathrm{~K}, \mathrm{MgNi}_{2}$ that was not detected under $1023 \mathrm{~K}$ was formed with about $5 \mu \mathrm{m}$ thickness between the nickel substrate and $\mathrm{Mg}_{2} \mathrm{Ni}$ layer. In the $\mathrm{Mg}-\mathrm{Ni}$ phase diagram as shown in Fig. 6, ${ }^{9}$ no $\mathrm{Mg}_{2} \mathrm{Ni}$ exists over $1033 \mathrm{~K}$ (m.p. of $\mathrm{Mg}_{2} \mathrm{Ni}: 1033 \mathrm{~K}$ ) and only the solid $\mathrm{MgNi}_{2}$ remained co-existing with the liquid phase. The intermetallic compound of $\mathrm{Mg}_{2} \mathrm{Ni}$ was, therefore, formed on the $\mathrm{MgNi}_{2}$ layer during the cooling process.

The current efficiency of electrodeposition was calculated from the thickness of the film by the same way described in the previous paper. ${ }^{5}$. The best current efficiency was $21.4 \%$ for the specimen formed under the electrolysis condition with $0.10 \mathrm{~A} \mathrm{~cm}^{-2}$ for $3.6 \mathrm{ks}$ at $873 \mathrm{~K}$. The reason for this low current efficiency is considered as follows. When magnesium is electrodeposited on the nickel substrate and forms the Ni-poor alloy phases, part of these alloy phases drop into the molten salts if the alloy phase is liquid as understanding from the $\mathrm{Mg}-\mathrm{Ni}$ phase diagram. ${ }^{9)}$

It is said that there may be a close relationship between the electrolysis temperature and the phase diagram.

4. 1. 3 Discussion for formation of intermetallic compound Intermetallic compounds such as $\mathrm{LaNi}_{5}$ (in the $\mathrm{La}-\mathrm{Ni}$ system), $\mathrm{TiFe}_{2}$ (in the $\mathrm{Ti}-\mathrm{Fe}$ system), and $\mathrm{CaNi}_{5}$ (in the $\mathrm{Ca}-\mathrm{Ni}$ system) formed by molten salts electrolysis are equilibrated with each substrate. ${ }^{5}$ In the $\mathrm{Mg}-\mathrm{Ni}$ system, however, $\mathrm{Mg}_{2} \mathrm{Ni}$ that is not equilibrated with the nickel substrate was formed on nickel. Considering the X-ray diffraction patterns, $\mathrm{MgNi}_{2}$ in equilibrium with the nickel substrate was detected in Fig. 4 (a). However, the $\mathrm{MgNi}_{2}$ phase was not observed clearly as shown in Fig. 5 (b) (3). Therefore, it is considered that very thin $\mathrm{MgNi}_{2}$ film may be formed between $\mathrm{Mg}_{2} \mathrm{Ni}$ and the nickel substrate.

The relationship between the electrolysis conditions and the alloy phase formed is summarized in shown in Fig. 7. The reaction rate of the electrode-

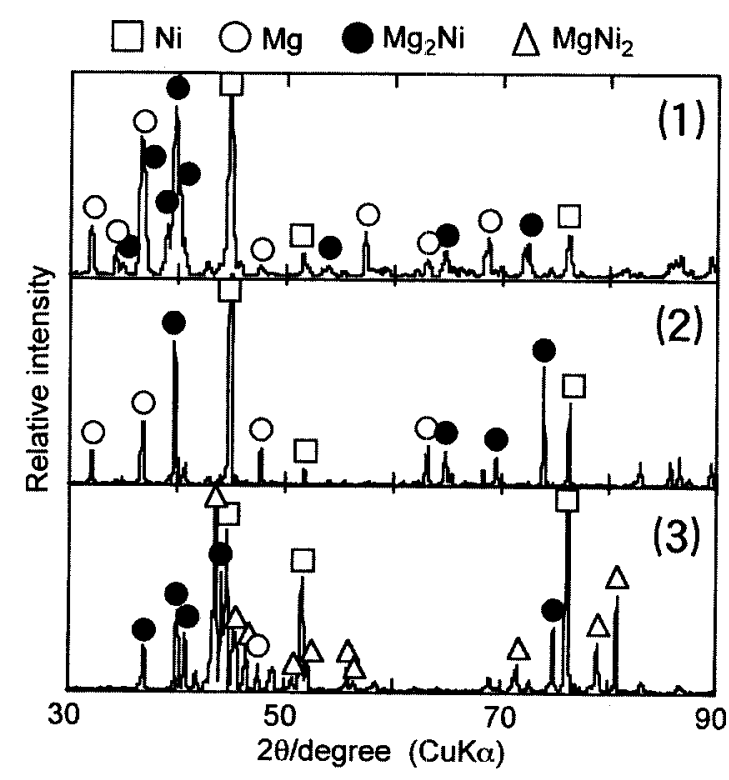

(a)

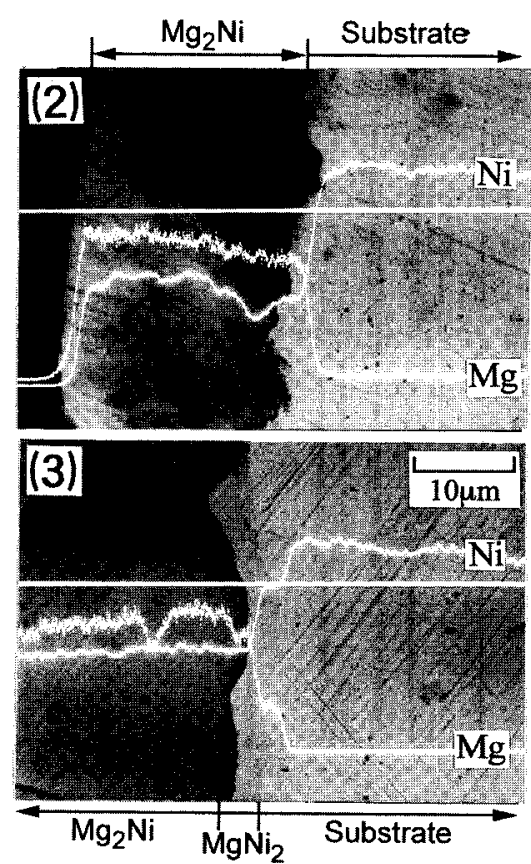

(b)

Fig. 5 X-ray diffraction patterns of the surface (a) and EPMA line analysis of the cross section of the specimen (b)

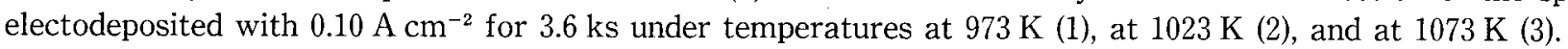




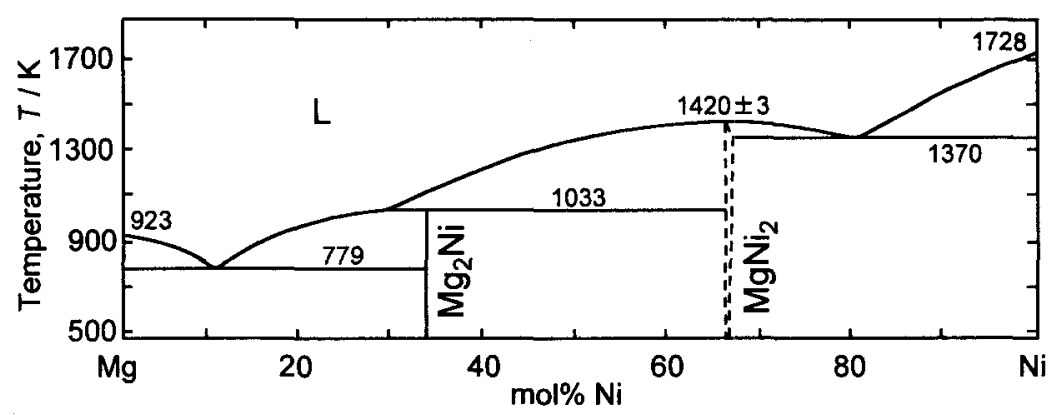

Fig. 6 Binary phase diagram of the $\mathrm{Mg}-\mathrm{Ni}$ system. ${ }^{9)}$

posit with the substrate is fast when the electrolysis temperature is high. But if the electrolysis is conducted with high current density at higher temperature, magnesium may remained on the surface (domain (a) above an oblique line in Fig. 7). At temperatures higher than $1033 \mathrm{~K}$ corresponding to the melting point of $\mathrm{Mg}_{2} \mathrm{Ni}$, the $\mathrm{MgNi}_{2}$ phase is formed between the nickel substrate and the $\mathrm{Mg}_{2} \mathrm{Ni}$ phase (domain (c)). Thus, the phase mainly consisting of $\mathrm{Mg}_{2} \mathrm{Ni}$ can be obtained if the electrolysis is conducted with condition controlled within the domain (b) in Fig. 7.

\section{2 Hydrogen absorption properties}

Hydrogen absorption and desorption tests for specimens electrodeposited in molten salts were conducted in 30 mass \% $\mathrm{KOH}$ solution at $298 \mathrm{~K}$. The results of hydrogen absorption tests of $\mathrm{Mg}-\mathrm{Ni}$ alloys are shown in Fig. 8. The charge capacity represents the amount of absorbed hydrogen per mass unit of the alloy film. Curves (a), (b), and (c) in Fig. 8 represent the $\mathrm{Mg}-\mathrm{Ni}$ specimens electrodeposited with $0.02 \mathrm{~A}$ $\mathrm{cm}^{-2}$ for $18 \mathrm{ks}$ at $873 \mathrm{~K}$, with $0.10 \mathrm{~A} \mathrm{~cm}^{-2}$ for $3.6 \mathrm{ks}$ at $873 \mathrm{~K}$, and with $0.10 \mathrm{~A} \mathrm{~cm}^{-2}$ for $3.6 \mathrm{ks}$ at $1023 \mathrm{~K}$, respectively. Although the same test was conducted with the nickel substrate for reference, hydrogen was

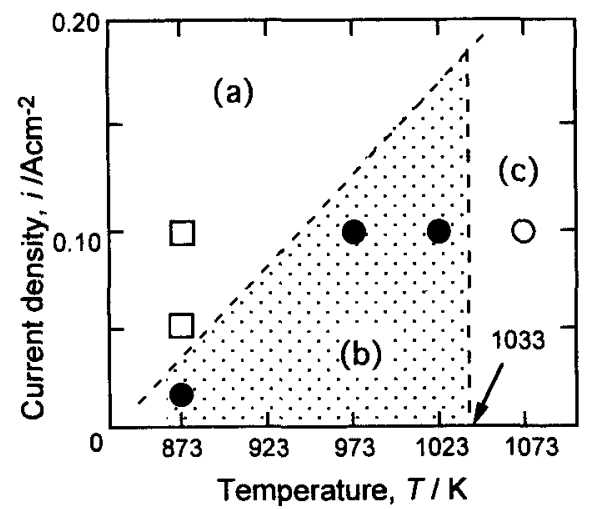

Fig. 7 Scheme for the relationship between the electrolysis conditions and formed alloy phase. : Single phase $\mathrm{Mg}_{2} \mathrm{Ni}$ formed, $\mathrm{O}: \mathrm{MgNi}_{2}$ formd between the nickel substrate and $\mathrm{Mg}_{2} \mathrm{Ni}$ layer, and $\square$ : Magnesium was left on the $\mathrm{Mg}_{2} \mathrm{Ni}$ layer. not absorbed. Each specimen $((\mathrm{a}) \sim(\mathrm{c}))$ absorbed hydrogen. Specimen (b) consisting of a mixture of magnesium and $\mathrm{Mg}_{2} \mathrm{Ni}$ on the surface absorbed hydrogen more than specimen (a) with only $\mathrm{Mg}_{2} \mathrm{Ni}$. It is considered that not only $\mathrm{Mg}_{2} \mathrm{Ni}$ but also magnesium absorbed hydrogen. Specimen (c) consisting of only $\mathrm{Mg}_{2} \mathrm{Ni}$ layer electrodeposited at $1023 \mathrm{~K}$ absorbed more than (a) and (b), because differences of the surface condition, the size of the particle and the internal defects as observed in Fig. 4 (b) (3) may affect the hydrogen absorption.

Hydrogen desorption tests were also conducted, however, it was found that a small amount of the absorbed hydrogen was desorbed (4 -9\% of absorbed hydrogen desorbed). In this study, activation treatment of the alloy was not conducted in order to compare with our previous works. Therefore, activation treatment may be necessary for $\mathrm{Mg}$-based alloy.

The Mg-Ni hydrogen absorption alloy can be formed as a film on the substrate in direct and single process combining molten salts electrolysis and diffusion. There is a possibility that this method can be applied to other functional materials.

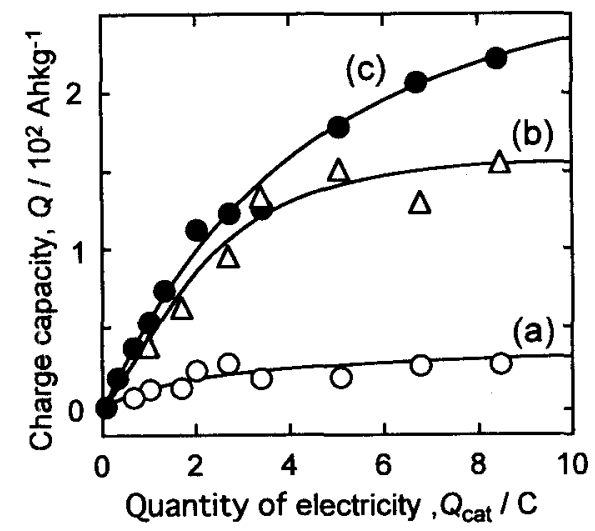

Fig. 8 Hydrogen absorption tests in 30 mass \% $\mathrm{KOH}$ solution at $298 \mathrm{~K}$. Magnesium was electrodeposited with $0.02 \mathrm{~A} \mathrm{~cm}^{-2}$ for $18 \mathrm{ks}$ at $873 \mathrm{~K} \mathrm{(a),} \mathrm{with} 0.10 \mathrm{~A} \mathrm{~cm}^{-2}$ for 3.6

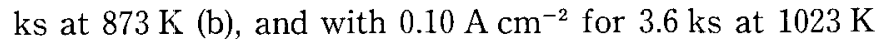
(c). 


\section{Conclusion}

The formation of the hydrogen absorption film, $\mathrm{Mg}_{2} \mathrm{Ni}$, was attempted by molten salts electrolysis and diffusion process. The formed intermetallic compound film was examined by X-ray diffraction analysis and EPMA line analysis of the cross section. The relationship between the electrolysis conditions and the formed alloy phases was examined and the following results were obtained;

(1) Hydrogen absorption film, $\mathrm{Mg}_{2} \mathrm{Ni}$, was obtained in the $\mathrm{Mg}-\mathrm{Ni}$ system. The mixed phase consisting of magnesium and $\mathrm{Mg}_{2} \mathrm{Ni}$ was also formed on the sur face electrodeposited with a high current density of $0.10 \mathrm{~A} \mathrm{~cm}^{-2}$ for $3.6 \mathrm{ks}$ at $873 \mathrm{~K}$.

(2) $\mathrm{Mg}_{2} \mathrm{Ni}$ single layer was formed with a low current density of $0.02 \mathrm{~A} \mathrm{~cm}^{-2}$ or under high temperature at $1023 \mathrm{~K}$. At $1073 \mathrm{~K}, \mathrm{Mg}_{2} \mathrm{Ni}$ was formed between the nickel substrate and the $\mathrm{Mg}_{2} \mathrm{Ni}$ layer.

(3) Although the $\mathrm{Mg}-\mathrm{Ni}$ alloys produced by the electrodeposition process absorbed hydrogen in 30 mass \% KOH, only a small amount of absorbed hydrogen was released in a subsequent desorption test.

\section{References}

1) H. Tamura, Hydrogen Storage Alloys : Fundamentals and Frontier Technologies, (Eds. H. Uehara, Y. Ohsumi, and T. Sakai), N. T. S, Tokyo, p. 249 (1998).

2) H. Aoyagi, K. Aoki, and T. Masumoto, J. Alloys and Compounds, 231, 804 (1995).

3) T. Sakai, H. Ishikawa, H. Miyamura, N. Kuriyama, S. Yamada, and T. Iwasaki, J. Electrochem. Soc., 138, 908 (1991).

4) S. Kamasaki, K. Kamei, and Y. Nasu, J. the Surface Finishing Soc. of Japan, 43, 30 (1992).

5) H. Yamamoto, K. Kuroda, R. Ichino, and M. Okido, Denki Kagaku (presently Electrochemistry), 66, 549 (1998).

6) M. Okido, R. Ichino, and R. Tamura, MOLTEN SALTS $X$, p. 320, The Electrochemical Society, Pennington, NJ (1996).

7) M. Okido, R. Ichino, and R. Tamura, J. The Surface Finishing Soc. of Japan, 46, 1139 (1992).

8) Y. Ohsumi, Hydrogen Absorption Alloy, Agune, Tokyo (1993).

9) T. B. Massalski , H. Okamoto, P. R. Subramanian, and L. Kacprzak, Binary Alloy Phase Diagrams Second Edition, The Material Information Society, United States of America, p. 1529 of Vol. 2, p. 932 of Vol. 1 (1990). 